University for Business and Technology in Kosovo

UBT Knowledge Center

UBT International Conference

2015 UBT International Conference

Nov 7th, 9:00 AM - 5:00 PM

\title{
E-learning systems in higher education institutions: An outlook of their use in the Western Balkan Region
}

\author{
Blerta Abazi Chaushi \\ South East European University, b.abazi@seeu.edu.mk \\ Agron Chaushi \\ South East European University, a.caushi@seeu.edu.mk \\ Florije Ismaili \\ South East European University
}

Follow this and additional works at: https://knowledgecenter.ubt-uni.net/conference

Part of the Computer Sciences Commons, and the Digital Communications and Networking Commons

\section{Recommended Citation}

Chaushi, Blerta Abazi; Chaushi, Agron; and Ismaili, Florije, "E-learning systems in higher education institutions: An outlook of their use in the Western Balkan Region" (2015). UBT International Conference. 109.

https://knowledgecenter.ubt-uni.net/conference/2015/all-events/109

This Event is brought to you for free and open access by the Publication and Journals at UBT Knowledge Center. It has been accepted for inclusion in UBT International Conference by an authorized administrator of UBT Knowledge Center. For more information, please contact knowledge.center@ubt-uni.net. 


\title{
E-learning systems in higher education institutions: An outlook of their use in the Western Balkan Region
}

\author{
Blerta Abazi Chaushi ${ }^{1}$, Agron Chaushi ${ }^{1}$, Florije Ismaili ${ }^{2}$ \\ ${ }^{1}$ Faculty of Business and Economics, SEE-University, \\ 1200 Tetovo. Macedonia \\ ${ }^{2}$ Faculty of Contemporary Sciences, SEE-University, \\ 1200 Tetovo, Macedonia \\ \{b.abazi, a.caushi\}@seeu.edu.mk
}

\begin{abstract}
This study provides a review of the literature on e-learning systems evolution and environments. The argument is that e-learning systems should be embedded in the core strategy of the institution. To support this premise, studies for e-learning are analyzed and six recommendations are drawn for universities to follow in order to have successful e-learning environments. The main contribution of this study, however, is the identification of the trends and statistics regarding the elearning usage in the Balkan region. These stats are identified through a survey conducted in 40 universities in 10 countries from this region. The results show that more than $70 \%$ of the universities have adopted LMS, which does not fall short behind when compared with universities in the world. Also, the results show that around $64 \%$ of the private universities develop LMS in-house, compared with around $38 \%$ of the public universities, which have funding from the governments and can purchase vendor based solutions. However, the results from the survey suggest that public universities in these countries are more prone to open-source rather than vendor based.
\end{abstract}

Keywords: e-learning., learning management systems, higher education institutions

\section{Introduction}

In this study, the impact of technology in University setting is discussed, and the importance of elearning environments is explored. An analysis of the phases of evolution of e-learning and e-learning environments is carried out. The importance of adding e-learning into the strategic plans of the universities is presented through an examination of the literature. The result from the analysis materializes through six recommendations that can be adopted by institutions of $\mathrm{HE}$ to better integrate their e-learning systems with their strategic plans and operations. Moreover, the application of the types of e-learning system in Balkan countries is examined. In this study 40 Universities in 10 countries (Macedonia; Albania; Bosnia and Herzegovina; Bulgaria; Croatia; Greece; Kosovo; Montenegro; Serbia; and Slovenia) are surveyed to attain the levels of e-learning adoption and the systems they use. This survey was conducted in year 2014. A limitation of the study is that the sample of the universities is not large enough to generalize for the Balkan region, but since in this sample only renowned universities from each country are surveyed, this limitation is alleviated.

\section{Literature Review}

The changing landscape of Higher Education Institutions (HEIs) in order to achieve thriving learning experience and continuous improvement is being perceived through constant adjustments in the approaches to new technology [1]. Knowledge development in the information age is a technologically aided activity [2]. Learning Management Systems (LMS), distance education and online learning, have become an important feature of online service delivery within the Higher Education Information Services sector, requiring close attention to issues of functionality, 
sustainability and usability. In today's university landscape, a key strategic issue regarding online learning is not whether to engage, but how [3].

\subsection{Learning Management Systems evolution}

Learning management systems (LMS) can be defined as: "a software application that automates the administration, tracking, and reporting of training events" [4]. The earliest LMS can be dated back to Sydney's Automatic Teacher in 1924, a primitive system that automated grading of multiple choice tests [5]. This is seen as the first endeavor to what we call today Learning Management Systems. In 1956 SAKI was invented [6], a system that automatically adjusted the difficulty of questions based on the performance of the user. In 1969 Arpanet, the precursor of today's web was created, which will have a huge impact in the way LMS was developed. It was until 1997 that interactive learning network was designed. Courseinfo is amongst the first players in this sphere [7]. In year 2002 Moodle was released, which is today one of the most used LMS in university settings in the world (moodle.net/stats). And today, most modern LMS are hosted in the cloud, which make much easier the process of moving to e-learning environment since there is no need to install or maintain a system and especially no need for the burden of in-house development [8]. In the year 2005, online programs become available at colleges and universities in different formats, as certificates, diplomas, degrees, or post-baccalaureate programs [9]. Over the next few years, we see a slight shift from the traditional classrooms to more network based teaching, and the beginning of the transformation of the institutions [10]. The last decade is the time of the rapid development of technology-based learning tools. According to a study conducted by Ingerman and Yang [11]: "This rise in strategic importance is evidence that technology has moved beyond the data center and institutional administrative systems and is now part of daily life for faculty and students".

\subsection{E-Learning and its integration in the strategy of the university}

E-learning must be seen as a strategic initiative and operation of the institution that takes this endeavor. Successful e-learning implementation depends on building a strategy that meets the needs of the learners and the business goals of the institution [12]. Several advices for universities that have adopted or plan to adopt e-learning, and especially for the institutions that want to achieve operational effectiveness as well as increase of quality in terms of e-learning usage can be drawn. Consistent with a research conducted by Elaine Allen and Jeff Seaman based on responses from over 2,800 Chief Academic Officers (CAOs) and academic leaders, 69.1\% of the respondents agreed that online learning is of strategic importance for the university [13]. The reason for its strategic importance is that the number of the students that take online courses has increased a lot in this 10 year period. It is a fact that around $72 \%$ of universities had online offerings even ten years ago. A major change that is worth mentioning is that a far larger proportion of higher education institutions have moved from offering only online courses to providing complete online programs (62.4\% in 2012 as compared to $34.5 \%$ in 2002) [13]. An analysis of the studies regarding the importance of e-learning in university setting [14]-[18], as well as the studies regarding the e-learning frameworks, especially one of the most famous, the TPACK framework [19]-[25], with a focus on the strategic role of e-learning and importance in active learning, better teaching and creation of engaging learning environments, led to the proposal of the following six suggestions for improvement:

1. Institutions of Higher Education should make e-learning initiatives part of the institution's strategic plan and budget, and set specific goals for e-learning initiatives.

2. HEIs should try to centralize essential e-learning technology services as much as possible because of the greater efficiency and seamless integration of e-learning services.

3. E-learning should be viewed as critical to the mission of the university and the provision of e-learning services should have high priority within IT. The reliability of the technology used in e-learning should be seamless.

4. The university should create a clear path that will demonstrate the merits of e-learning for both traditional face-to-face and online classrooms. It is important to keep the faculty and students interested in this new learning environment, and it is a good add-on to implementing a faculty e-learning mentoring program using faculty who have already taught e-learning courses. 
5. Universities should ensure that the chosen technologies for e-learning are scalable, by creating a plan for the number of courses/programs that will roll out e-learning initiatives in the coming years

6. Universities should make sure that the chosen technologies adaptable - not all the courses and programs have a need for the same technology.

\section{Methodology}

For the purpose of this study 40 universities from 10 countries in Balkan region including Macedonia, Albania, Greece, Bulgaria, Serbia, Kosovo, Montenegro, Bosnia and Herzegovina, Croatia and Slovenia were surveyed. The following questions: Does the university use any learning management systems; what type of system do they use, and what specific product they use - were asked and answers were obtained. The data was acquired by conducting a short survey that covered only the abovementioned issues. The websites of these universities were also visited, and in cases there was not enough information, representatives of the university were contacted by asking questions that were needed for this study. As mentioned in the introduction of this study, the data might not be $100 \%$ accurate since not all universities in this region were included, and this poses a limitation. However, since this sample is consisted of renowned universities from each country, this limitation is reduced, and the results of this study are important and reflect the reality of current state of e-learning in the region. These figures are just a sample, and data might vary if all the universities were surveyed.

\section{Results of the Survey within Universities in the Balkan Region}

According to our study, about $72 \%$ of the universities in the Balkan region have some system in place for uploading course content as lecture notes, assignments, etc. This number, in contrast with the Universities in the world, does not stand behind very much. According to latest CDS survey, which surveys more than 2000 universities around the world, $65 \%$ have online learning platform in place, $17 \%$ use the cloud services, $9 \%$ have some sort of a system, and only $9 \%$ of institutions do not have discussion to date about online learning [17].

Table 4: LMS adoption level in the Western Balkan Countries

\begin{tabular}{lrcc}
\hline Heading level & Public & Private & Overall \\
\hline Do not have an LMS & $\mathbf{3 0 . 4 3 \%}$ & $\mathbf{2 3 . 5 3 \%}$ & $\mathbf{2 7 . 5 0 \%}$ \\
Have implemented an LMS & $\mathbf{6 9 . 5 7 \%}$ & $\mathbf{7 6 . 4 7 \%}$ & $\mathbf{7 2 . 5 0 \%}$ \\
\hline
\end{tabular}

During this study, an analysis was conducted to see whether there is a difference in implementation of LMS depending on the type (public, private) of the university. In this study 17 universities were private and 23 universities were public. Based on the data that were collected, there is no significant difference between and private universities on implementation of LMS. As can be seen from Table 4, around $77 \%$ of private universities and $70 \%$ of the public universities have implemented a LMS.

Also, an interesting conclusion from this survey, as can be seen from the Figure 5: LMS Adoption Level by Country

, is that only Greece, Bulgaria, Croatia and Montenegro have a LMS in place in all of the surveyed universities, whereas in the rest of the countries there are still universities that are not using any LMS as a part of regular or distance learning studies. 


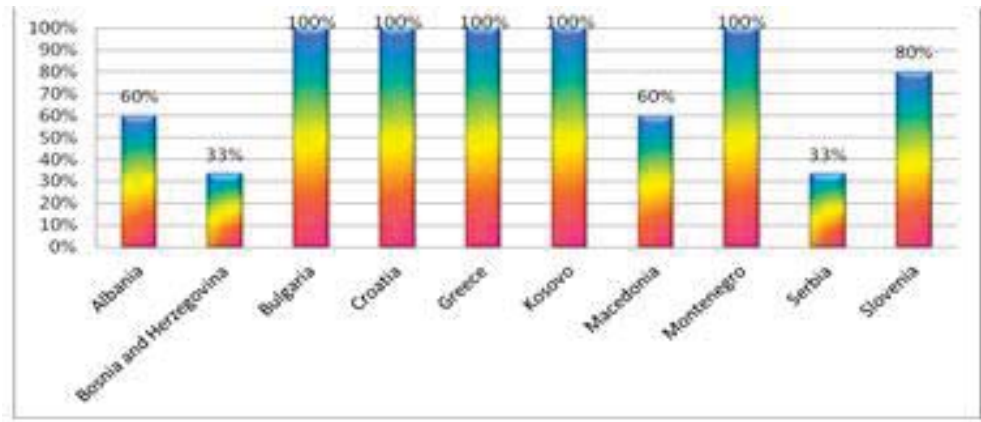

Figure 5: LMS Adoption Level by Country

Another question that this study was trying to find an answer to was to find out what type of LMS do universities use (see Figure 6-left). The results show that, of the universities that have a Learning Management System in place, around 43\% have created their LMS in-house whereas the others have implemented a readily available package. From the LMS packages, Moodle is definitely the most popular one. We assume that the main determinants for choosing Moodle are that it is free, it is opensource and it has a big community. Interestingly, there can be seen a similarity in the preference of a LMS package, with some minor differences. The major difference can be seen in the preference of
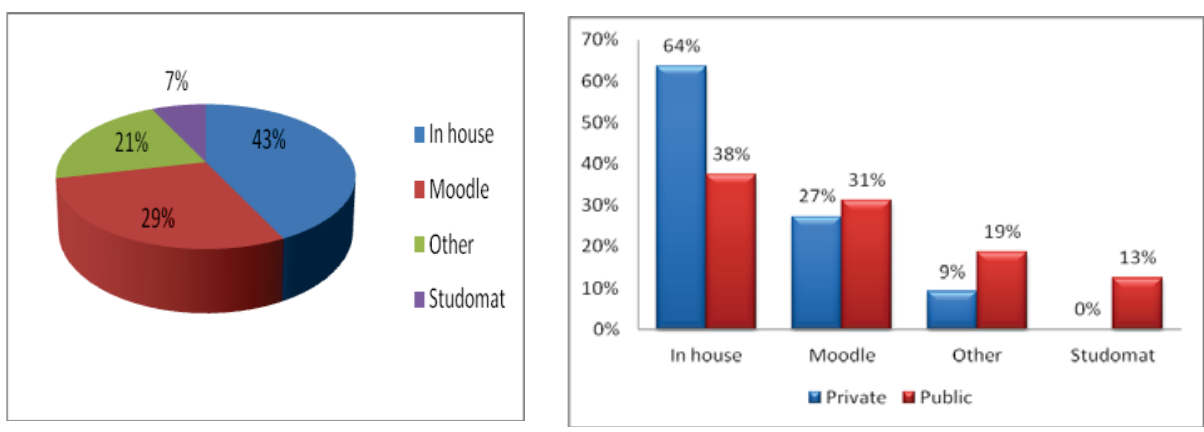

Figure 6: Types of LMS adopted Overall (left) and in Public and Private Universities(right)

choosing a readily available solution or building the LMS in-house. $64 \%$ of the private universities have chosen to build their own LMS versus $38 \%$ of the public universities with the same choice (see Figure 6-right). It is worth to mention that all the analyzed public universities in Croatia use and LMS called Studomat.

\section{Findings and Conclusion}

In general, the results of this study show that, Balkan region is not lacking in implementing LMS as a technology or platform for e-learning. The tendency is to develop a LMS in-house or adopt an open source or free LMS which is understandable due to lack of funding for IT. However, this study is falling short in answering to the question how much are these LMSs used in reality and to what extent do they fulfill their mission of transferring knowledge through online media. These questions need a broader research where many universities will be involved and a better qualitative and quantitative data will be collected to answer the questions that are addressed but not answered as a part of this research. In summary, there is a growing recognition of the need for e-learning solutions in the Balkan region. Institutions are becoming aware of the trends in e-learning. As it was showed in the above section, most of the universities are making their steps in adopting LMS and some of the universities have started with offering some distance learning and online programs. From the analysis, it was noticed that all these universities that were part of the survey, either had open source, either build inhouse LMS. None of these universities has gone for a vendor based solution because they are in the 
beginning stages of e-learning and they do not want to spend funds for a vendor based solutions. However, it is encouraging to see that both, public and private universities embrace the trends in higher education. In spite of this, we should highlight that e-learning is not only a technological matter. Rather, it is a process involving academic staff, students, and pedagogical content. For this reason, it is important for universities to have a strategic approach to e-learning. It takes a lot more than providing a technological platform for e-learning in order to be successful in transferring knowledge to students using electronic media. If higher education institutions view e-learning purely as a technology, they will be doomed to fail [26].

\section{References}

1 L. Abazi-Bexheti, "Development of a learning content management systems," J. Online Learn. Teach., vol. 2, pp. 1034-1048, 2008.

2 D. R. Garrison, T. Anderson, and W. Archer, "A theory of critical inquiry in online distance education," Handb. Distance Educ., vol. 1, pp. 113-127, 2003.

3 S. Grajek, "Top-Ten IT Issues, 2014," EduCause, 2014.

4 R. Ellis, "Field Guide to Learning Management Systems," ASTD, 2009.

5 L. T. Benjamin, "A history of teaching machines.," Am. Psychol., vol. 43, no. 9, pp. 703-712, 1988.

6 G. Pask, "SAKI: Twenty-five years of adaptive training into the microprocessor era," Int. J. Man-Mach. Stud., vol. 17, no. 1, pp. 69-74, Jul. 1982.

7 D. M. Fahey, "Blackboard COURSEINFO: Supplementing In-Class Teaching with the Internet," Hist. Comput. Rev., vol. 16, no. 1, pp. 29-37, Jan. 2000.

8 F. M. M. Neto and F. V. Brasileiro, Eds., Advances in Computer-Supported Learning:. IGI Global, 2006.

9 B. I. Dewey and P. B. DeBlois, “Top-ten IT issues, 2006,” Educ. Rev., vol. 41, no. 3, p. 58, 2006.

10 B. Abazi Caushi, A. Caushi, and Z. Dika, "A Comprehensive Aproach to Technology Issues and Challenges for Higher Education Institutions," in 12th International conference e-Society, Madrid, Spain, 2013, pp. 177-184.

11 B. L. Ingerman and C. Yang, "Top-Ten Issues, 2011."

12 E. Engelbrecht, "A look at e-learning models: investigating their value for developing an elearning strategy," Progressio, vol. 25, no. 2, p. p-38, 2003.

13 E. Allen and J. Seaman, Changing Course: Ten Years of Tracking Online Education in the United States. ERIC, 2013.

14 M. J. Rosenberg, E-learning: Strategies for delivering knowledge in the digital age, vol. 3. McGraw-Hill New York, 2001.

15 S. Alexander, "E-learning developments and experiences," Educ. Train., vol. 43, no. 4/5, pp. 240-248, 2001.

16 R. H. Wild, K. A. Griggs, and T. Downing, "A framework for e-learning as a tool for knowledge management,” Ind. Manag. Data Syst., vol. 102, no. 7, pp. 371-380, 2002.

17 Paramythis and S. Loidl-Reisinger, "Adaptive learning environments and e-learning standards," in Second European Conference on e-Learning, 2003, vol. 1, pp. 369-379.

18 M. Ebner, "E-Learning 2.0= e-Learning 1.0+ Web 2.0?," in Availability, Reliability and Security, 2007. ARES 2007. The Second International Conference on, 2007, pp. 1235-1239.

19 M. J. Koehler, T. S. Shin, and P. Mishra, "How do we measure TPACK? Let me count the ways," Educ. Technol. Teach. Knowl. Classr. Impact Res. Handb. Framew. Approaches, pp. $16-31,2011$.

$20 \mathrm{Hu}$ and V. Fyfe, "Impact of a new curriculum on pre-service teachers' Technical, Pedagogical and Content Knowledge (TPACK)," Curric. Technol. Transform. Unkn. Future Proc. Ascilite Syd. 2010, 2010.

21 L. Archambault and K. Crippen, "Examining TPACK among K-12 online distance educators in the United States," Contemp. Issues Technol. Teach. Educ., vol. 9, no. 1, pp. 71-88, 2009.

22 Sahin, "Development of survey of technological pedagogical and content knowledge (TPACK).," Turk. Online J. Educ. Technol.-TOJET, vol. 10, no. 1, pp. 97-105, 2011.

23 M. Bower, J. G. Hedberg, and A. Kuswara, “A framework for Web 2.0 learning design,” Educ. Media Int., vol. 47, no. 3, pp. 177-198, 2010. 
24 E. Rahimi, J. Van den Berg, and W. Veen, "A framework for designing enhanced learning activities in web2. 0-based Personal Learning Environments," in World Conference on Educational Multimedia, Hypermedia and Telecommunications, 2013, vol. 2013, pp. 2222 2231.

25 Maor and P. Roberts, "Does the TPACK framework help to design a more engaging learning environment?," in World Conference on Educational Multimedia, Hypermedia and Telecommunications, 2011, vol. 2011, pp. 3498-3504.

26 G. Ssekakubo, H. Suleman, and G. Marsden, "Issues of Adoption: Have e-Learning Management Systems Fulfilled Their Potential in Developing Countries?," in Proceedings of the South African Institute of Computer Scientists and Information Technologists Conference on Knowledge, Innovation and Leadership in a Diverse, Multidisciplinary Environment, New York, NY, USA, 2011, pp. 231-238. 